\title{
Significance of genetic polymorphisms in patients with nonalcoholic fatty liver disease
}

\author{
Hisamitsu Miyaaki ${ }^{1} \cdot$ Kazuhiko Nakao $^{1}$
}

Received: 26 February 2017/ Accepted: 2 March 2017/Published online: 13 March 2017

(C) Japanese Society of Gastroenterology 2017

\begin{abstract}
Because of recent advances in genetic research such as genome-wide association studies, the underlying genetic mechanisms of nonalcoholic fatty liver disease (NAFLD) pathophysiology have been elucidated. Here, we present a review of the current literature on the impact of genetic polymorphisms in patients with NAFLD. These genetic polymorphisms, which regulate lipid metabolism, glucose metabolism, and the renin-angiotensin system, are involved in NAFLD onset, steatosis, inflammation, fibrosis, and hepatocellular carcinoma (HCC). Among these genetic polymorphisms, many studies and meta-analyses have demonstrated that position 148 (rs738409 C/G) of the patatin-like phospholipase domain-containing protein (PNPLA3) is a genetic factor associated with NAFLD pathophysiological features, such as hepatic fat level, hepatic inflammation, fibrosis, and HCC. However, the impact of genetic polymorphisms on NAFLD pathophysiology appears to differ among ethnic groups. Therefore, further studies with larger sample sizes are needed for each ethnic group.
\end{abstract}

Keywords Genetic polymorphism · NAFLD · NASH · Steatosis · Inflammation · Fibrosis

Hisamitsu Miyaaki

miyaaki-hi@umin.ac.jp

1 Department of Gastroenterology and Hepatology, Nagasaki University Graduate School of Biomedical Sciences, 1-7-1 Sakamoto, Nagasaki 852-8501, Japan

\section{Introduction}

Nonalcoholic fatty liver disease (NAFLD) is one of the most common liver diseases worldwide. A large Japanese cohort study indicated that $29.7 \%$ of the adult population has NAFLD [1]. NAFLD is associated with metabolic syndrome, including obesity, hyperlipidemia, hypertension, and diabetes [2,3]. Therefore, NAFLD is considered part of the metabolic syndrome [3]. With an increasing number of patients with metabolic disease, the prevalence of NAFLD patients is increasing in Japan [1]. NAFLD encompasses a wide range of diseases, including non-alcoholic fatty liver (NAFL), non-alcoholic steatohepatitis (NASH), fibrosis, cirrhosis, and hepatocellular carcinoma (HCC) [4, 5]. It has been determined that several environmental factors, such as lifestyle and enteral environment, affect the development of NASH. However, disease state in NAFLD is difference in individual at any body mass index or visceral fat. Furthermore, studies of twin subjects have suggested the heritability of NAFLD [6]. Therefore, NAFLD could be influenced by genetic variants. Indeed, several single-nucleotide polymorphisms (SNPs) have been reported to affect pathophysiology in patients with chronic liver disease including NAFLD through a genome-wide association study (GWAS). Over the last 10 years, many studies have also revealed the role of genetic factors in the development of steatosis, fibrosis, cirrhosis, and HCC in NAFLD. In this review, we discuss the genetic factors implicated in steatosis, steatohepatitis, fibrosis progression, cirrhosis, and HCC in NAFLD patients. 
Table 1 Characteristics of genetic polymorphisms involved in lipid metabolism

\begin{tabular}{|c|c|c|c|c|}
\hline Gene & Patient ethnicity & Polymorphism & Association & Reference \\
\hline PNPLA3 & $\begin{array}{l}\text { Mixed (Hispanic/Caucasian/African } \\
\text { American) }\end{array}$ & rs738409 I148M (C/G) & Steatosis & {$[8]$} \\
\hline PNPLA3 & Japanese & $\mathrm{I} 148 \mathrm{M}(\mathrm{C} / \mathrm{G})$ & Steatosis, fibrosis & {$[9,10]$} \\
\hline PNPLA3 & Taiwan, Pediatric & $\mathrm{I} 148 \mathrm{M}(\mathrm{C} / \mathrm{G})$ & Steatosis & {$[18]$} \\
\hline MTP & Caucasian (French) & $-493(\mathrm{G} / \mathrm{T})$ & Steatohepatitis & {$[26]$} \\
\hline MTP & Japanese & $-493(\mathrm{G} / \mathrm{T})$ & $\begin{array}{l}\text { Intracellular triglyceride } \\
\text { accumulation }\end{array}$ & {$[27]$} \\
\hline MTP & Chinese & $\begin{array}{l}\mathrm{rs} 1800804(-164 \mathrm{~T} / \mathrm{C}) \mathrm{rs} 1057613 \mathrm{~A} / \mathrm{G} \\
\quad \mathrm{rs} 3805335 \mathrm{C} / \mathrm{T}\end{array}$ & NAFLD & [29] \\
\hline APOC3 & India & rs651821 C-482T, T-455C & NAFLD, insulin resistance & [29] \\
\hline APOC3 & Caucasian (Italian/United Kingdom) & rs651821 C-482T, T-455C & Favorable lipid profile & {$[30]$} \\
\hline TM6SF2 & $\begin{array}{l}\text { Mixed (Hispanic/Caucasian/African } \\
\text { American) }\end{array}$ & rs58542926 & Hepatic steatosis & {$[34]$} \\
\hline PPAR $\alpha$ & Brazilian & Leu162Val & Fibrosis & {$[38]$} \\
\hline $\operatorname{PPAR} \alpha$ & Chinese & Val227Ala & NAFLD & [40] \\
\hline $\operatorname{PPAR} \gamma$ & Germany & Pro12Ala & NAFLD & [43] \\
\hline PPAR $\gamma$ & Indian & Pro12Ala & NAFLD, overweight & [44] \\
\hline
\end{tabular}

PNPLA3 patatin-like phospholipase domain-containing protein, $M T P$ microsomal triglyceride transfer protein, APOC3 apolipoprotein C3, $P P A R$ peroxisome proliferator-activated receptor, $N A F L D$ nonalcoholic fatty liver disease

\section{Genetic polymorphisms of lipid metabolism (Table 1)}

About half of Japanese patients with NAFLD have hyperlipidemia [7]. Lipid metabolism in the liver and peripheral tissue plays a critical role in NAFLD onset and progression. Thus, there are many reports of gene polymorphisms involved in lipid metabolism that are associated with NAFLD and NAFLD fibrosis progression.

\section{Patatin-like phospholipase domain-containing protein (PNPLA3)}

A polymorphism in PNPLA3 at position 148 of the protein, which causes an isoleucine (rs738409-C) to methionine (rs738409-G) substitution, was identified as a genetic factor associated with increased hepatic fat level and hepatic inflammation by GWAS [8]. Subsequently, many studies of this polymorphism have been reported. In addition, the rs738409-GG genotype was associated with a higher risk of liver fibrosis, cirrhosis, and HCC [9-11].

The PNPLA3 gene encodes the protein adiponutrin, which is expressed in the liver [12], where the replacement of isoleucine with methionine reduces its hydrolytic activity for triglycerides [13]. PNPLA3 is also expressed in adipose tissue [14] and the adrenal gland [15], and it is closely related to the major triglyceride hydrolete in peripheral fat tissue [16].

In the Japanese population, the rs738409-GG genotype was associated with susceptibility to NAFLD and with histological fibrosis stage [9, 10]. In addition, the rs738409-G allele was associated with hepatic steatosis as measured by ultrasonography and with overweight in pediatric subjects in Italy and Taiwan [17, 18]. The rs738409-G allele also increases the risk of HCC in patients with NAFLD. Compared to the CC genotype, the GC and GG genotypes exhibit increased risk for HCC (ORs 2.52 and 12.19, respectively) [19]. The frequency of the rs738409-GG genotype is higher among the Japanese (23\%) and Hispanic (33\%) populations than among the African American (1.6\%) or European American (4\%) populations [8-10].

Liver steatosis is observed in $18-40 \%$ patients after liver transplantation. Finkenstedts et al. reported that the rs738409 genotype of the recipient, but not the donor was associated with post-transplant steatosis [20]. In contrast, in our recent study, an rs738409-GG genotype in the donor was a predictor of post-transplant steatosis (in submission). In addition, the donor PNPLA3 genotype was reported to be the predictor of post-transplant outcome among liver transplant recipients with hepatitis $\mathrm{C}$ virus [21]. Finally, the rs738409-G allele has been reported to be associated with steatosis and/or fibrosis and HCC in other liver diseases, including hepatitis $\mathrm{B}$ and $\mathrm{C}$ and alcoholic liver disease [22].

\section{Microsomal triglyceride transfer protein (MTP)}

MTP has a pivotal role in metabolizing hepatic triglycerides and very low-density lipoproteins (VLDL) for lipid 
export from the liver [23]. Therefore, MTP plays an important role in lipid metabolism. Some previous studies reported that functional polymorphisms of MTP were associated with reduced low-density lipoprotein (LDL) levels [24]. Among French and Japanese patients, a polymorphism (promoter $-493 \mathrm{G}$-allele) in the MTP gene is correlated with down-regulation of the MTP gene, corresponding to NASH and more severe steatosis [25, 26]. In contrast, in a Brazilian study, there was no association between the $-493 \mathrm{G} / \mathrm{T}$ polymorphism and NAFLD [27]. The frequency of the MTP gene polymorphism (-493 GGgenotype) was similar among Japanese $(60.7 \%)$, French (55.7\%), and Brazilian (59.3\%) individuals [25-27]. Finally, Peng et al. examined 580 NAFLD patients and 580 healthy controls in China. Multivariate analysis demonstrated that rs1800804 $(-164 \mathrm{~T} / \mathrm{C})$ was associated with an increased risk of NAFLD, while rs1057613 A/C and rs $3805335 \mathrm{C} / \mathrm{T}$ were associated with a decreased risk of NAFLD [28].

\section{Apolipoprotein C3 (APOC3)}

APOC 3 regulates lipoprotein lipase activity. An APOC3 variant (C-482T, T-455C, or both) resulted in a $30 \%$ increase in the plasma concentration of apolipoprotein $\mathrm{C} 3$ as compared with that in the wild-type. There was also an increase in plasma triglycerides and tetinyl fatty acid ester concentrations by a factor of approximately two after an oral fat-tolerance test. The average hepatic triglyceride content was higher in individuals carrying the APOC 3 rs651821 variant alleles (C-482T, T-455C, or both) than in wild-type homozygotes. In addition, the prevalence of NAFLD was $38 \%$ among the APOC3 variant-allele group and $0 \%$ among wild-type homozygotes. Subjects with NAFLD also exhibited marked insulin resistance [29]. In contrast, in Italy and the United Kingdom, the APOC3 wild-type genotype was associated with a more favorable lipid profile but not with insulin resistance, NASH, or increased fibrosis [30]. Moreover, among Finnish subjects, $A P O C 3$ variants were not associated with liver fat content due to NAFLD [31]. The prevalence of variant APOC3 alleles was found to be $79.7 \%$ in Asian Indian, $66.8 \%$ in Italian, and 80\% in Finnish individuals [29-31].

\section{Transmembrane 6 superfamily member 2 (TM6SF2)}

A TM6SF2 variant was identified in an exome-wide association study. This variant was not associated with body mass index (BMI), homeostatic model assessment of insulin resistance (HOMA-IR), or alcohol intake. Knockdown of TM6SF2 in mice increased liver triglyceride content by threefold and decreased VLDL secretion by
$50 \%$. Thus, these data indicate that TM6SF2 activity is required for normal VLDL secretion. The TM6SF2 variant associated with hepatic triglyceride content is an adenineto-guanine substitution at coding nucleotide 499. Moreover, the TM6SF2 variant genotype affects inflammation and liver fibrosis stage [32]. However, a recent study in a Japanese cohort demonstrated that the TM6SF2 genotype was not associated with steatosis, inflammation, or liver fibrosis stage [33]. TM6SF2 (rs10401969) also influences the total cholesterol level and was associated with a reduction in coronary artery disease events in a large sample of 20,597 cases and 61,046 controls (OR 0.90, $\left.p=2 \times 10^{-4}\right)[34]$.

\section{Peroxisome proliferator-activated receptor (PPAR)}

PPARs are members of a family of nuclear receptors and play an important role in lipid metabolism. Members of the PPAR family include PPAR $\alpha$, PPAR $\gamma$, and PPAR $\delta$. PPAR $\alpha$ regulates fatty acid uptake and the oxidation of fatty acids. It is expressed in tissues such as the liver, heart, muscle, and brown adipose tissue [35]. In a Brazilian study, the polymorphism Leu162Val in PPAR $\alpha$ was associated with NAFLD fibrosis [36], while in an Italian study, the frequency of the Leu162Val polymorphism did not differ between patients with NAFLD and a control group [37]. However, the frequency of another PPAR $\alpha$ polymorphism, Val227Ala, was significantly different between subjects with NAFLD and a control group in China [38]. In Japan, Yamakawa et al. reported that the Val227Ala allele was associated with total cholesterol [39].

$\operatorname{PPAR} \gamma$ is expressed in adipocytes, macrophages, and muscle, where it regulates abiogenesis, lipid storage, and glucose metabolism [40]. The polymorphism Pro12Ala in PPAR $\gamma$ among German subjects was more frequently found in NAFLD patients than in controls. However, the Pro12Ala polymorphism was not associated with NAFLD progression [41]. Similarly, in Italian NAFLD patients, Pro12Ala was not associated with NAFLD onset, liver damage, or insulin resistance [37]. Gupta et al. showed that the prevalence of the Pro12Ala variant was higher among Indian NAFLD subjects than among controls. In addition, the Pro12Ala variant was also associated with overweight [42]. This result suggests that the Pro12Ala variant plays a role in obesity-related NAFLD.

\section{Genetic polymorphisms of glucose metabolism (Table 2)}

Glucose intolerance, including insulin resistance, is a risk factor for the development of steatosis, NASH, and cirrhosis in patients with NAFLD. 
Table 2 Characteristics of genetic polymorphisms involved in glucose metabolism, renin-angiotensin, and others

\begin{tabular}{|c|c|c|c|c|}
\hline Gene & Patients ethnicity & Polymorphism & Association & Reference \\
\hline ENPP1 & $\begin{array}{l}\text { Caucasian (Italian, United } \\
\text { Kingdom) }\end{array}$ & Lys121Gln & $\begin{array}{l}\text { Body weight, dyslipidemia, } \\
\text { fibrosis }\end{array}$ & [48] \\
\hline IRS-1 & $\begin{array}{l}\text { Caucasian (Italian, United } \\
\text { Kingdom) }\end{array}$ & Gly972Arg & Dyslipidemia, fibrosis & {$[48]$} \\
\hline Adiponectin & Italian & $+45 \mathrm{~T} / \mathrm{G}$ & $\begin{array}{l}\text { Hepatic steatosis, } \\
\text { necroinflammatory grade }\end{array}$ & {$[52]$} \\
\hline Adiponectin & Japanese & $-493(\mathrm{G} / \mathrm{T})$ & Steatohepatitis & {$[53]$} \\
\hline AGT & Japanese & rs7079 SNP & Steatohepatitis & \\
\hline AGTR1 & Japanese & $\begin{array}{l}\text { rs } 3772622, \text { rs } 3772633, \text { rs } 2276736, \text { rs } 3772630, \\
\text { rs } 3772627\end{array}$ & NAFLD, fibrosis & {$[58]$} \\
\hline IL28B & Italian & rs12979860 (CC) & Inflammation, fibrosis & {$[63]$} \\
\hline
\end{tabular}

ENPP1 ectoenzyme nucleotide pyrophosphate phosphodiesterase, IRS insulin receptor substrate, AGT angiotensinogen, AGTRI angiotensin II type 1 receptor, $I L 28 B$ interleukin $28 \mathrm{~B}$

\section{Ectoenzyme nucleotide pyrophosphate phosphodiesterase 1 (ENPP) and insulin receptor substrate (IRS)}

Insulin resistance is a key factor in NAFLD pathophysiology. The presence of metabolic syndrome is associated with the severity of NAFLD [2, 3]. In addition, insulin resistance is associated with liver damage and fibrosis [43]. In hepatocytes, insulin binds to the insulin receptor, activating insulin receptor substrate (IRS)-1 and IRS-2 and in turn leading to the phosphorylation of transcription factors that regulate the glucose level [44]. ENPP1 inhibits the insulin signal and causes insulin resistance [45]. Among the genes involved in the regulation of the insulin signal, it has been reported that genetic polymorphisms of ENPP1 and IRS-1 influence insulin receptor activity and are associated with liver damage [46]. In studies in Italy and the United Kingdom, multivariate analysis revealed that the ENPP1 121Gln and IRS-1 972Arg polymorphisms, present in 28.7 and $18.1 \%$ of patients respectively, were independently associated with advanced fibrosis in NAFLD patients. In addition, these polymorphisms were associated with a reduction in AKT status, reflecting insulin resistance and disease severity in patients with NAFLD [46].

\section{Adiponectin}

Adiponectin is a cytokine secreted from adipose tissue, also known as an adipokine. Adiponectin plays an important role in hepatic and peripheral glucose metabolism and has an anti-inflammatory function [47]. Several studies have reported that systemic levels of adiponectin are reduced in NASH patients [48] and correlated with liver fibrosis [49]. Musoo et al. demonstrated that in an Italian cohort, an adiponectin genotype $(+45 \mathrm{~T} / \mathrm{G})$ was associated with hepatic steatosis, necroinflammatory grade, and postprandial adiponectin levels [50]. Similarly, associations between $+45 \mathrm{~T} / \mathrm{G}$ and HOMA-IR and liver fibrosis were reported among Japanese NAFLD patients [51]. In an Indian population, $-11377 \mathrm{GG}$ and $+45 \mathrm{~T} / \mathrm{G}$ were associated with NAFLD [52]. The frequency of $+45 \mathrm{GG}$, a well-known adiponectin SNP, was found to vary in Japanese (NAFLD $10.9 \%$, control $10.4 \%$ ) and Indian (NAFLD 5.1\%, control $0.8 \%$ ) individuals with and without NAFLD [51, 52].

\section{Genetic polymorphisms of hypertension (Table 2)}

Hypertension is one of the diseases included in the diagnosis of metabolic syndrome, and it is associated with the progression of NAFLD [2, 53]. The activity of the reninangiotensin system influences hypertension and liver fibrosis in chronic liver disease [54].

\section{Angiotensinogen (AGT) and angiotensin II type 1 receptor (AGTR1)}

AGT is well known to be an important regulator of blood pressure. Some previous reports have shown that genetic polymorphisms of AGT and angiotensin receptor (AGTR) influence serum AGT levels and hypertension. The frequency of the rs7079-A allele in NASH patients $(21.0 \%)$ was found to be significantly higher than that in healthy controls (13.0\%). Regarding haplotypes of the AGT gene, the CTA/- frequency in NASH patients was significantly higher than that in healthy controls. In addition, the diastolic blood pressure in patients with the CTA/- haplotype was significantly higher than that in patients with other haplotypes [55].

Angiotensin II function involves AGTR1. This receptor is expressed on hepatic stellate cells, which play an important role in liver fibrosis progression. Five SNPs (rs3772622, 
rs3772633, rs2276736, rs3772630, and rs3772627) in AGTR1 were found to be significantly associated with NAFLD. Moreover, there was a significant association between rs3773622 genotypes and liver fibrosis [56].

\section{Genetic variants in mediators of inflammation (Table 2)}

\section{Interleukin 28B (IL28B)}

Genetic polymorphisms of IL28B (rs12979860 CC and rs809917 TT) have been reported as predictors of the sustained virological response (SVR) after interferon therapy in patients with chronic hepatitis C [57-59]. Moreover, previous studies have demonstrated that this $I L 28 B$ polymorphism was associated with severity of disease, steatosis, and fibrosis in patients with chronic hepatitis C [60-62]. In Italian patients with NAFLD, multivariate analysis showed that the rs12979860-CC genotype is independently associated with moderate to severe inflammation and severe fibrosis [63]. However, in a cohort of Caucasian North American patients, the rs12979860-CC genotype did not affect the histological features of patients with NAFLD [64]. In contrast, meta-analysis showed that rs8099917-TT was significantly associated with a reduced risk of severe steatosis in patients with chronic hepatitis C [62].

In conclusion, a variety of genetic polymorphisms appear to influence NAFLD onset and the severity of steatosis, necroinflammation, and fibrosis. However, the influence of genetic polymorphisms on NAFLD pathophysiology seems to differ among ethnic groups. Therefore, validation studies in each ethnic group should be performed in the future.

\section{Compliance with ethical standards}

Conflict of interest The authors declare that they have no conflict of interest.

\section{References}

1. Eguchi Y, Hyogo H, Ono M, et al. Prevalence and associated metabolic factors of nonalcoholic fatty liver disease in the general population from 2009 to 2010 in Japan: a multicenter large retrospective study. J Gastroenterol. 2012;47:586-95.

2. Miyaaki H, Ichikawa T, Nakao K, et al. Clinicopathological study of nonalcoholic fatty liver disease in Japan: the risk factors for fibrosis. Liver Int. 2008;28:519-24.

3. Marchesini G, Brizi M, Bianchi G, et al. Nonalcoholic fatty liver disease: a feature of the metabolic syndrome. Diabetes. 2001;50:1844-50.

4. Ekstedt M, Franzen LE, Mathiesen UL, et al. Long-term followup of patients with NAFLD and elevated liver enzymes. Hepatology. 2006;44:865-73.
5. Bugianesi E, Leone N, Vanni E, et al. Expanding the natural history of nonalcoholic steatohepatitis: from cryptogenic cirrhosis to hepatocellular carcinoma. Gastroenterology. 2002;123:134-40.

6. Loomba R, Schork N, Chen $\mathrm{CH}$, et al. Heritability of hepatic fibrosis and steatosis based on a prospective twin study. Gastroenterology. 2015;149:1784-93.

7. Nakahara T, Hyogo H, Yoneda M, et al. Type 2 diabetes mellitus is associated with the fibrosis severity in patients with nonalcoholic fatty liver disease in a large retrospective cohort of Japanese patients. J Gastroenterol. 2014;49:1477-84.

8. Romeo S, Kozlitina J, Xing C, et al. Genetic variation in PNPLA3 confers susceptibility to nonalcoholic fatty liver disease. Nat Genet. 2008;40:1461-5.

9. Hotta K, Yoneda M, Hyogo H, et al. Association of the rs 738409 polymorphism in PNPLA3 with liver damage and the development of nonalcoholic fatty liver disease. BMC Med Genet. 2010;11:172.

10. Kawaguchi T, Sumida Y, Umemura A, et al. Genetic polymorphisms of the human PNPLA3 gene are strongly associated with severity of non-alcoholic fatty liver disease in Japanese. PLoS ONE. 2012;7:e38322.

11. Sookoian S, Pirola CJ. Meta-analysis of the influence of I148M variant of patatin-like phospholipase domain containing 3 gene (PNPLA3) on the susceptibility and histological severity of nonalcoholic fatty liver disease. Hepatology. 2011;53:1883-94.

12. Lake AC, Sun Y, Li JL, Kim JE, et al. Expression, regulation, and triglyceride hydrolase activity of Adiponutrin family members. J Lipid Res. 2005;46:2477-87.

13. He S, McPhaul C, Li JZ, et al. A sequence variation (I148M) in PNPLA3 associated with nonalcoholic fatty liver disease disrupts triglyceride hydrolysis. J Biol Chem. 2010;285:6706-15.

14. Baulande S, Lasnier F, Lucas M, et al. Adiponutrin, a transmembrane protein corresponding to a novel dietary- and obesitylinked mRNA specifically expressed in the adipose lineage. J Biol Chem. 2001;276:33336-44.

15. Kershaw EE, Hamm JK, Verhagen LA, et al. Adipose triglyceride lipase: function, regulation by insulin, and comparison with adiponutrin. Diabetes. 2006;55:148-57.

16. Zimmermann R, Strauss JG, Haemmerle G, et al. Fat mobilization in adipose tissue is promoted by adipose triglyceride lipase. Science. 2004;306:1383-6.

17. Romeo S, Sentinelli F, Cambuli VM, et al. The $148 \mathrm{M}$ allele of the PNPLA3 gene is associated with indices of liver damage early in life. J Hepatol. 2010;53:335-8.

18. Lin YC, Chang PF, Hu FC, et al. A common variant in the PNPLA3 gene is a risk factor for non-alcoholic fatty liver disease in obese Taiwanese children. J Pediatr. 2011;158:740-4.

19. Liu YL, Patman GL, Leathart JB, et al. Carriage of the PNPLA3 rs738409 C $>$ G polymorphism confers an increased risk of nonalcoholic fatty liver disease associated hepatocellular carcinoma. J Hepatol. 2014;61:75-81.

20. Finkenstedt A, Auer C, Glodny B, et al. Patatin-like phospholipase domain-containing protein 3 rs738409-G in recipients of liver transplants is a risk factor for graft steatosis. Clin Gastroenterol Hepatol. 2013;11:1667-72.

21. Dunn W, O’Neil M, Zhao J, et al. Donor PNPLA3 rs738409 genotype affects fibrosis progression in liver transplantation for hepatitis C. Hepatology. 2014;59:453-60.

22. Dongiovanni P, Donati B, Fares R, et al. PNPLA3 I148M polymorphism and progressive liver disease. World J Gastroenterol. 2013;19:6969-78.

23. Levy E, Stan S, Delvin E, et al. Localization of microsomal triglyceride transfer protein in the Golgi: possible role in the assembly of chylomicrons. J Biol Chem. 2002;277:16470-7.

24. Karpe F, Lundahl B, Ehrenborg E, et al. A common functional polymorphism in the promoter region of the microsomal 
triglyceride transfer protein gene influences plasma LDL levels. Arterioscler Thromb Vasc Biol. 1998;18:756-61.

25. Bernard S, Touzet S, Personne I, et al. Association between microsomal triglyceride transfer protein gene polymorphism and the biological features of liver steatosis in patients with type II diabetes. Diabetologia. 2000;43:995-9.

26. Namikawa C, Shu-Ping Z, Vyselaar JR, et al. Polymorphisms of microsomal triglyceride transfer protein gene and manganese superoxide dismutase gene in non-alcoholic steatohepatitis. J Hepatol. 2004;40:781-6.

27. Oliveira CP, Stefano JT, Cavaleiro AM, et al. Association of polymorphisms of glutamate-cystein ligase and microsomal triglyceride transfer protein genes in non-alcoholic fatty liver disease. J Gastroenterol Hepatol. 2010;25:357-61.

28. Peng XE, Wu YL, Lu QQ, et al. MTTP polymorphisms and susceptibility to non-alcoholic fatty liver disease in a Han Chinese population. Liver Int. 2014;34:118-28.

29. Petersen KF, Dufour S, Hariri A, et al. Apolipoprotein C3 gene variants in nonalcoholic fatty liver disease. $\mathrm{N}$ Engl $\mathrm{J}$ Med. 2010;362:1082-9.

30. Valenti L, Nobili V, Al-Serri A, et al. The APOC3 T-455C and $\mathrm{C}-482 \mathrm{~T}$ promoter region polymorphisms are not associated with the severity of liver damage independently of PNPLA3 I148 M genotype in patients with nonalcoholic fatty liver. J Hepatol. 2011;55:1409-14.

31. Hyysalo J, Stojkovic I, Kotronen A, et al. Genetic variation in PNPLA3 but not APOC3 influences liver fat in non-alcoholic fatty liver disease. J Gastroenterol Hepatol. 2012;27:951-6.

32. Kozlitina J, Smagris E, Stender S, et al. Exome-wide association study identifies a TM6SF2 variant that confers susceptibility to nonalcoholic fatty liver disease. Nat Genet. 2014;46:352-6.

33. Akuta N, Kawamura Y, Arase Y, et al. Relationships between genetic variations of PNPLA3, TM6SF2 and histological features of nonalcoholic fatty liver disease in Japan. Gut Liver. 2016;10:437-45.

34. Holmen OL, Zhang H, Fan Y, et al. Systematic evaluation of coding variation identifies a candidate causal variant in TM6SF2 influencing total cholesterol and myocardial infarction risk. Nat Genet. 2014;46:345-51.

35. Berger J, Moller DE. The mechanisms of action of PPARs. Annu Rev Med. 2002;53:409-35.

36. Domenici FA, Brochado MJ, Martinelli Ade L, et al. Peroxisome proliferator-activated receptors alpha and gamma2 polymorphisms in nonalcoholic fatty liver disease: a study in Brazilian patients. Gene. 2013;529:326-31.

37. Dongiovanni P, Rametta R, Fracanzani AL, et al. Lack of association between peroxisome proliferator-activated receptors alpha and gamma2 polymorphisms and progressive liver damage in patients with non-alcoholic fatty liver disease: a case control study. BMC Gastroenterol. 2010;10:102.

38. Chen S, Li Y, Li S, Yu C. A Val227Ala substitution in the peroxisome proliferator activated receptor alpha (PPAR alpha) gene associated with non-alcoholic fatty liver disease and decreased waist circumference and waist-to-hip ratio. J Gastroenterol Hepatol. 2008;23:1415-8.

39. Yamakawa-Kobayashi K, Ishiguro H, et al. A Val227Ala polymorphism in the peroxisome proliferator activated receptor alpha (PPARalpha) gene is associated with variations in serum lipid levels. J Med Genet. 2002;39:189-91.

40. Wu Z, Rosen ED, Brun R, Hauser S, et al. Cross-regulation of $\mathrm{C} / \mathrm{EBP}$ alpha and PPAR gamma controls the transcriptional pathway of adipogenesis and insulin sensitivity. Mol Cell. 1999;3:151-8.

41. Rey JW, Noetel A, Hardt A, et al. Pro12Ala polymorphism of the peroxisome proliferator-activated receptor gamma2 in patients with fatty liver diseases. World J Gastroenterol. 2010;16:5830-7.
42. Gupta AC, Chaudhory AK, Sukriti Pande C, et al. Peroxisome proliferators-activated receptor gamma2 Pro12Ala variant is associated with body mass index in non-alcoholic fatty liver disease patients. Hepatol Int. 2010;5:575-80.

43. Fracanzani AL, Valenti L, Bugianesi E, et al. Risk of severe liver disease in nonalcoholic fatty liver disease with normal aminotransferase levels: a role for insulin resistance and diabetes. Hepatology. 2008;48:792-8.

44. Accili D, Arden KC. FoxOs at the crossroads of cellular metabolism, differentiation, and transformation. Cell. 2004;117:421-6.

45. Grarup N, Urhammer SA, Ek J, et al. Studies of the relationship between the ENPP1 K121Q polymorphism and type 2 diabetes, insulin resistance and obesity in 7,333 Danish white subjects. Diabetologia. 2006;49:2097-104.

46. Dongiovanni P, Valenti L, Rametta R, et al. Genetic variants regulating insulin receptor signalling are associated with the severity of liver damage in patients with non-alcoholic fatty liver disease. Gut. 2010;59:267-73.

47. Wolf G. Adiponectin: a regulator of energy homeostasis. Nutr Rev. 2003;61:290-2.

48. Pagano C, Soardo G, Esposito W, et al. Plasma adiponectin is decreased in nonalcoholic fatty liver disease. Eur $\mathrm{J}$ Endocrinol. 2005;152:113-8.

49. Ma H, Gomez V, Lu L, et al. Expression of adiponectin and its receptors in livers of morbidly obese patients with non-alcoholic fatty liver disease. J Gastroenterol Hepatol. 2009;24:233-7.

50. Musso G, Gambino R, De Michieli F, et al. Adiponectin gene polymorphisms modulate acute adiponectin response to dietary fat: possible pathogenetic role in NASH. Hepatology. 2008;47:1167-77.

51. Tokushige $\mathrm{K}$, Hashimoto $\mathrm{E}$, Noto $\mathrm{H}$, et al. Influence of adiponectin gene polymorphisms in Japanese patients with non-alcoholic fatty liver disease. J Gastroenterol. 2009;44:976-82.

52. Gupta AC, Misra R, Sakhuja P, et al. Association of adiponectin gene functional polymorphisms $(-11377 \mathrm{C} / \mathrm{G}$ and $+45 \mathrm{~T} / \mathrm{G})$ with nonalcoholic fatty liver disease. Gene. 2012;496:63-7.

53. Marchesini G, Bugianesi E, Forlani G, et al. Nonalcoholic fatty liver, steatohepatitis, and the metabolic syndrome. Hepatology. 2003;37:917-23.

54. Yoshiji H, Kuriyama S, Yoshii J, et al. Angiotensin-II type 1 receptor interaction is a major regulator for liver fibrosis development in rats. Hepatology. 2001;34:745-50.

55. Ono $\mathrm{M}$, Ochi $\mathrm{T}$, Munekage $\mathrm{K}$, et al. Angiotensinogen gene haplotype is associated with the prevalence of Japanese non-alcoholic steatohepatitis. Hepatol Res. 2011;41:1223-9.

56. Yoneda M, Hotta K, Nozaki Y, et al. Association between angiotensin II type 1 receptor polymorphisms and the occurrence of nonalcoholic fatty liver disease. Liver Int. 2009;29:1078-85.

57. Ge D, Fellay J, Thompson AJ, et al. Genetic variation in IL28B predicts hepatitis $\mathrm{C}$ treatment-induced viral clearance. Nature. 2009;461:399-401.

58. Suppiah V, Moldovan M, Ahlenstiel G, et al. IL28B is associated with response to chronic hepatitis $\mathrm{C}$ interferon-alpha and ribavirin therapy. Nat Genet. 2009;41:1100-4.

59. Tanaka Y, Nishida N, Sugiyama M, et al. Genome-wide association of IL28B with response to pegylated interferon-alpha and ribavirin therapy for chronic hepatitis C. Nat Genet. 2009;41:1105-9.

60. Tillmann HL, Patel K, Muir AJ, Guy CD, et al. Beneficial IL28B genotype associated with lower frequency of hepatic steatosis in patients with chronic hepatitis C. J Hepatol. 2011;55:1195-200.

61. Abe H, Ochi H, Maekawa T, et al. Common variation of IL28 affects gamma-GTP levels and inflammation of the liver in chronically infected hepatitis C virus patients. J Hepatol. 2010;53:439-43. 
62. Sato M, Kondo M, Tateishi R, et al. Impact of IL28B genetic variation on $\mathrm{HCV}$-induced liver fibrosis, inflammation, and steatosis: a meta-analysis. PLoS ONE. 2014;9:e91822.

63. Petta S, Grimaudo S, Camma C, et al. IL28B and PNPLA3 polymorphisms affect histological liver damage in patients with non-alcoholic fatty liver disease. J Hepatol. 2012;56:1356-62.
64. Garrett ME, Abdelmalek MF, Ashley-Koch A, et al. IL28B rs12979860 is not associated with histologic features of NAFLD in a cohort of Caucasian North American patients. J Hepatol. 2013;58:402-3. 